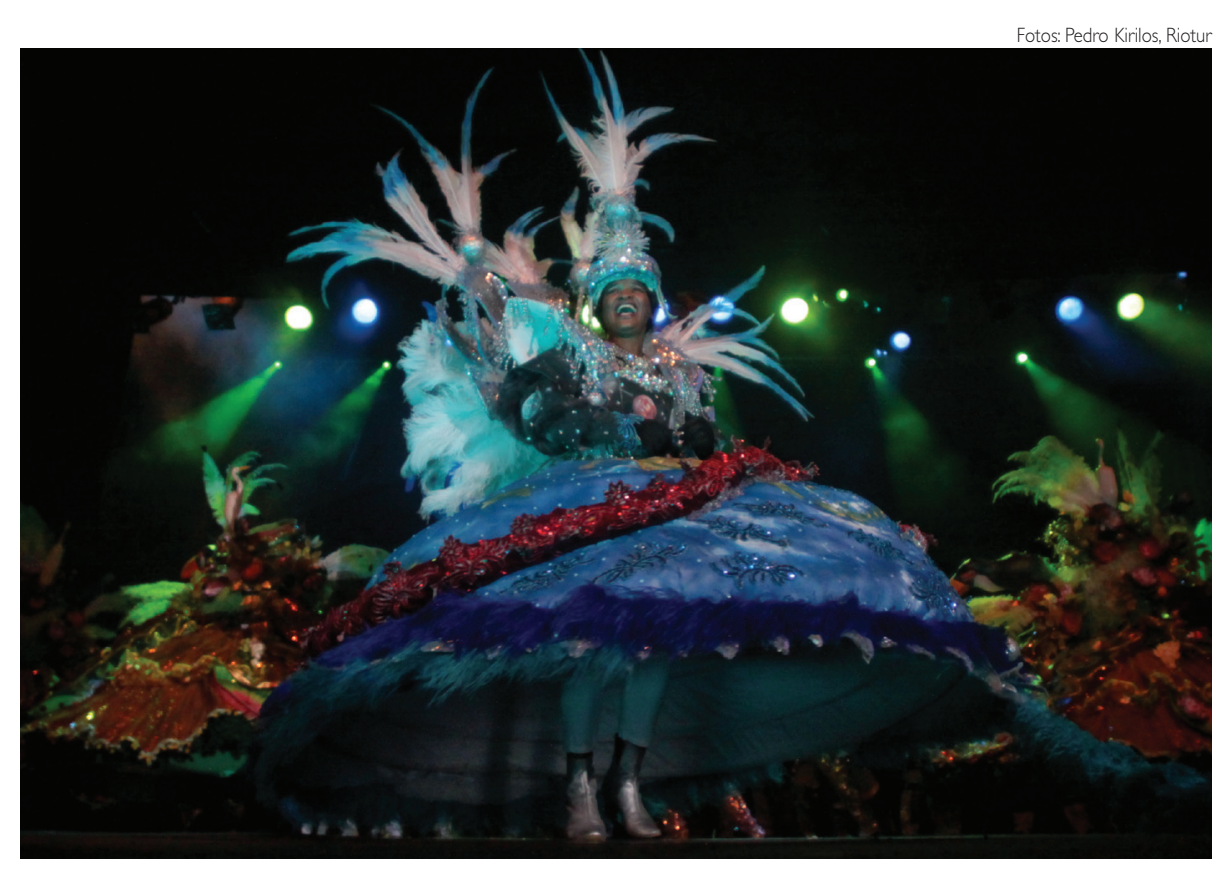

PATRIMÔNIO HISTÓRICO

\title{
RIO, CAPITAL DO SAMBA
}

Com muita frequência, a força de um gênero musical pode acabar impregnando a identidade de um lugar, um povo ou um país. Basta ouvir um fado de Amália Rodrigues ou Dulce Pontes e já estaremos pensando em Portugal; um tango cantado por Carlos Gardel ou nos acordes de Astor Piazzola, e Buenos Aires aparecerá frente aos nossos olhos; sem esquecer jamais do calor de Nova Orleans na voz de seus mestres que tocam o coração de amantes do jazz em todo planeta. Pois este é o espaço que o samba do Rio de Janeiro quer ocupar no imaginário de seus habitantes e dos milhares de turistas que visitam a cidade.

Se o samba nasceu ali, isto ainda é motivo de discussões entre especia- listas, mas não há dúvida sobre onde ele decidiu morar: no Rio de Janeiro. Em processo semelhante a tantas outras capitais musicais, o Rio se consolidou como o principal destino para quem deseja ver, ouvir, cantar e dançar samba. Terra de Noel Rosa, Cartola, Paulo da Portela, Zé Kéti, Paulinho da Viola, Bete Carvalho, Zeca Pagodinho e tantos outros, o samba se reinventa com novas influências, compositores e intérpretes, se mantém vivo e conquistando admiradores em todas as classes sociais. "Nenhuma manifestação cultural, hoje, reflete tão bem o espírito desta cidade quanto o samba", conta o jornalista Luiz Fernando Vianna, no livro Geografia carioca do samba (2004). Além das praias, da paisagem

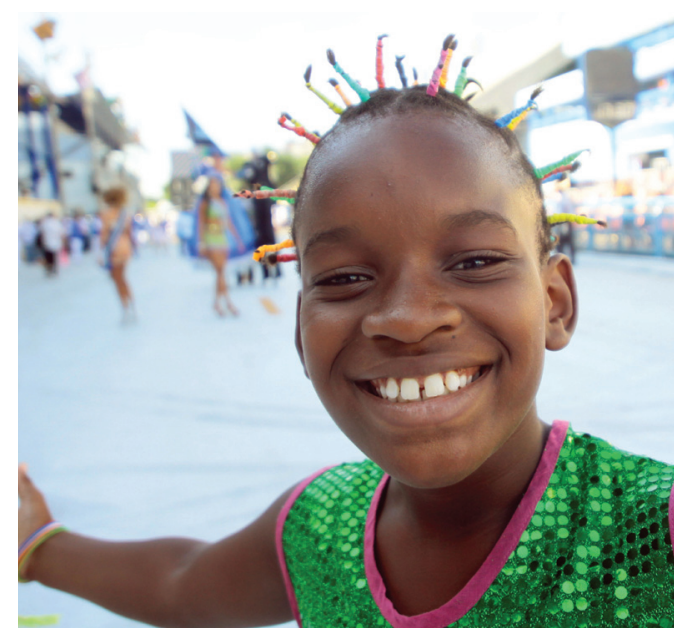

Cidade do Samba (à esq.) e (à dir.) menino desfila na Sapucaí em escola mirim da Inocentes da Caprichosos

exuberante, do Cristo Redentor e do Carnaval, o Rio de Janeiro se firma como capital desse gênero musical, atraindo turistas de dentro e de fora do país, durante $\mathrm{o}$ ano inteiro.

"A cidade vive um clima de samba como há muito não se via. E não é só na música, no teatro, em espetáculos como Sassaricando - e o Rio inventou a marchinha, na literatura com biografias de Vinicius de Moraes, Gonzaguinha e outros", conta José Augusto Kamel, que coordena o Laboratório de Engenharia do Entretenimento na Universidade Federal do Rio de Janeiro (UFRJ). A peça Sassaricando (2007) teve roteiro assinado pelo jornalista e pesquisador musical Sérgio $\mathrm{Ca}-$ bral e pela historiadora Rosa Maria Araújo, posteriormente virou $\mathrm{CD}$ e DVD. O musical incluiu mais de cem composiçōes de Noel Rosa, Lamartine Babo, Braguinha e outros. No texto de apresentação do DVD, Cabral explica que poucas 


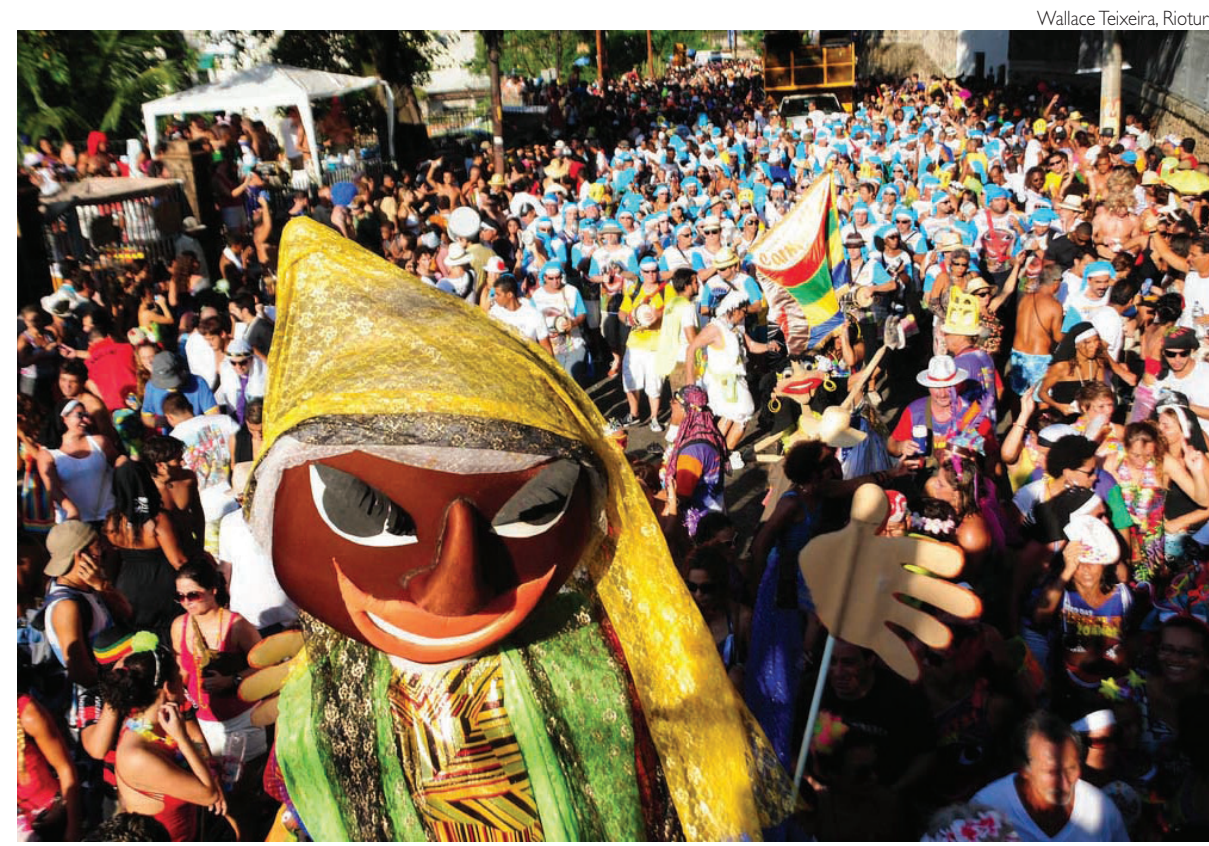

manifestações refletem com tanta exatidão a criatividade do compositor do Rio e o espírito carioca quanto as marchinhas. "São músicas que, ao mesmo tempo em que nos remetem a carnavais inesquecíveis, conservam o frescor e encantam crianças de todas as idades. Em outras palavras, são eternas”, escreve.

SAMBA DE MESA Para Kamel, além da efervescência do Carnaval, existe hoje um forte movimento do samba de mesa nos bares cariocas. "Na Lapa são incontáveis os estabelecimentos com programação semanal intensa", conta. Ao se tornar a principal atração das diversas casas de show e bares que se instalaram na Lapa a partir dos anos 1990, o samba também foi um dos responsáveis pela revitalização do bairro. A intensa movimentação cultural e noturna que caracteriza a Lapa, atualmente, acabou por recuperar uma tradição antiga do bairro que, nas décadas de 1930 e 1940, já era um reduto da boemia carioca. "Os resultados mais claros dessa nova onda foram a redescoberta da Lapa pela cidade; o aparecimento de uma classe média interessada em cantar, tocar e escutar samba; e a oportunidade de valorização de compositores do passado e de sambistas que mantêm essa tradição", conta Luiz Fernando Vianna no livro citado acima.

IDENTIDADE POR MEIO DA MÚSICA No século XIX, da fusão dos spirituals cantados pelos escravos com a música europeia trazida pelos imigrantes para os Estados Unidos, nasce o jazz, gênero musical que tem como marca a improvisação. Nova Orleans é considerada o berço do gênero. Foi a partir dali, pelo talento de músicos como Buddy Bolden e Louis Armstrong, que o jazz se difundiu para outras cidades norte-americanas. Fenômeno semelhante aconteceu em Buenos Aires, capital da

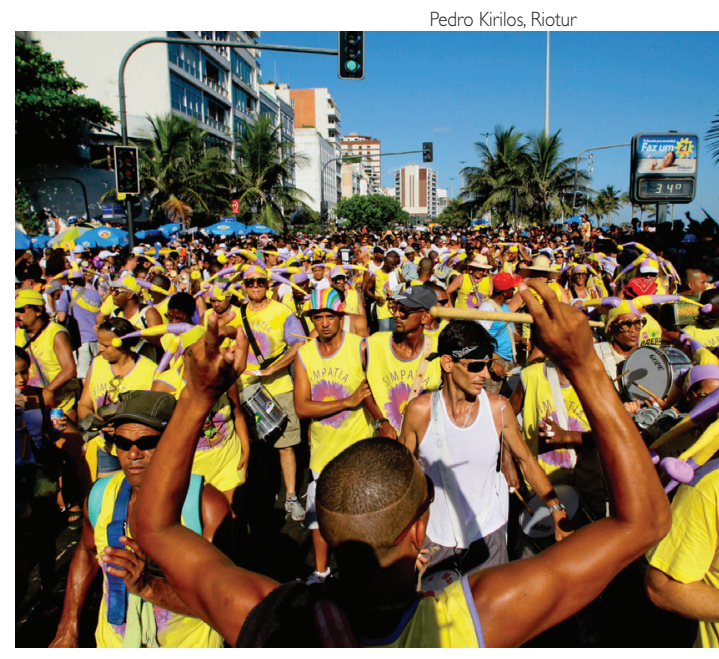

Bloco das Carmelitas (à esq.) e Simpatia é Quase Amor (à dir.): blocos arrastam multidões pelas ruas cariocas gratuitamente

Argentina, cuja marca musical é o tango. O ritmo nasceu como uma mistura das músicas dos imigrantes italianos e espanhóis que chegaram à Argentina no final do século XIX com a dos descendentes dos conquistadores espanhóis que já habitavam os pampas.

Assim como o samba e o jazz, o tango também era, em seu início, a expressão musical das populações mais pobres que moravam nos subúrbios de Buenos Aires. A dança era típica dos bordéis e tinha letras obscenas e violentas. Em artigo publicado na revista Mana (1997), do Museu Nacional, Rio de Janeiro, Eduardo Archetti, professor de antropologia social da Universidade de Oslo, Noruega, explica que a globalização do tango serviu para inventar uma "tradição", um espelho no qual os argentinos podiam se identificar, precisamente porque ali os "outros" começaram a vê-los. "A narrativa, a dança e a músi$\mathrm{ca}$, que formavam as diferentes faces 


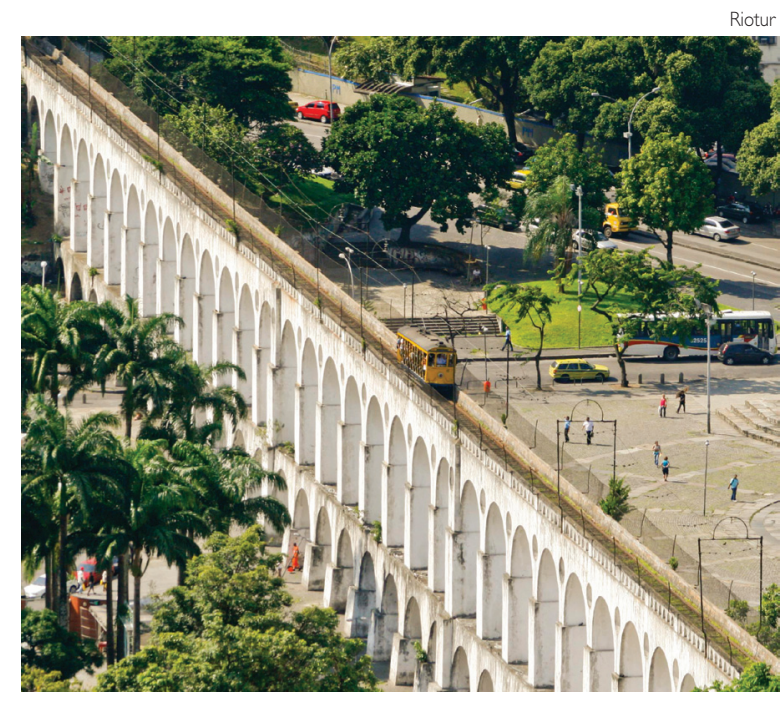

Sob os Arcos da Lapa, o samba tem presença marcante na programação semanal dos inúmeros bares

do tango, tornaram-se um elemento-chave na criação de um produto cultural argentino 'típico'”, disse o antropólogo. Levado para a cosmopolita Paris do início do século XX,

\section{ESCOLAS DE SAMBA FAZENDO ESCOLA}

Diariamente no Barracão 1 da Cidade do Samba 160 aprendizes, a maior parte deles de comunidades de baixa renda, participam de oficinas profissionalizantes com temas ligados à indústria do carnaval e ao setor administrativo das fábricas de alegorias. A escola foi organizada pela Liga Independente das Escolas de Samba do Rio de Janeiro, Liesa, com apoio do Ministério do Turismo. São 21 cursos com duração média de quatro meses. Aulas de escultura (em isopor, espuma, gesso e resina), adereços, maquiagem, corte e costura e figurinos estão entre as oficinas oferecidas. o tango virou febre, se espalhando para o resto do mundo, atraindo turistas para a capital portenha e tornando mundialmente conhecidos nomes como Carlos Gardel e Astor Piazzolla. No mesmo sentido, Kamel, da UFRJ, acredita que o desenvolvimento de um gênero musical é determinado, entre outros fatores, por uma demanda social em relacionar formas de entretenimento como expressão da identidade de um povo, nação ou etnia. "Os interesses econômicos mantêm essa oferta musical gerando investimentos que, por sua vez, criam outros produtos", afirma. Investidores podem vir do setor privado, como no caso do bairro da Lapa, ou do poder público cujos esforços atualmente também buscam fortalecer a imagem do Rio de Janeiro como capital do samba.

CARnAVAl 0 ano Inteiro Destaca-se, nesse sentido, a criação da Cidade do Samba, complexo com $92 \mathrm{mil}$ metros quadrados que concentra as atividades de preparação do Carnaval carioca, além de abrigar desfiles e shows ao longo do ano. O programa de visitação tem ingressos a preços populares ( $\mathrm{R} \$ 5$ a entrada inteira). Segundo a Secretaria da Cultura da cidade do Rio, foram investidos $\mathrm{R} \$$ 65 milhões, financiados pela prefeitura. O lugar, inaugurado em 2005 , tornou-se um novo ícone do samba, contribuindo para o fluxo permanente de turistas, movimentando a rede hoteleira e os serviços ligados ao turismo mesmo nos meses fora da alta temporada.

A Cidade do Samba fica no bairro da Gamboa, área portuária da cidade. O local foi escolhido por ser próximo do centro da cidade, facilitando o deslocamento das alegorias até o Sambódromo. Possui 14 galpões para montagem dos carros alegóricos e confecção de fantasias. Sua construção foi parte de um programa de revitalização da região. Como em outras cidades, a área portuária carioca vivia um processo de degradação desde a década de 1960, provocada pela obsolescência do porto e o esvaziamento dos bairros vizinhos. "Pensando na indústria do entretenimento, a Cidade do Samba pode alavancar toda a estrutura que comporta o Carnaval e o samba, desenvolvendo novos meios e aprimorando novas linguagens, como a da televisão”, acredita Kamel.

ALÉM DO TURISTA Há muito samba no Rio de Janeiro fora da Marquês de Sapucaí, onde reinam as grandes escolas. Durante o Carnaval boa parte dos bairros da cidade é tomada por blocos de rua que desfilam em cortejos animados pelas ruas, onde qualquer um pode participar. Desde 2009, o governo local, por meio de sua área de cultura, passou a apoiar esses grupos com o lançamento de editais. Segundo José Emílio Rondeau, assessor da Secretaria de Cultura, o objetivo é fomentar o samba popular fluminense. $\mathrm{O}$ primeiro edital contemplou 112 agremiaçōes com R \$ 600 mil. Para 2011 a previsão é conceder R \$ 800 mil, montante que é distribuído entre: blocos de 
enredo e de embalo, afoxés, ranchos, escolas de samba mirins, escolas do interior e bandas. "Os editais são importantes para preservar e estimular o carnaval de rua, do subúrbio e do interior do estado. Eles contemplam escolas de samba do terceiro e quarto grupos e escolas de samba mirins, agremiaçōes que não fazem parte da Liesa, a liga das escolas de samba que se apresentam no Sambódromo", detalha Rondeau.

MIS EM COPACABANA A preocupação com a preservação e divulgação do gênero que já é marca da cidade está, também, no novo Museu da Imagem e do Som (MIS), que está sendo construído na Av. Atlântica, em Copacabana. "Embora seja mundialmente conhecida como a capital do samba, não há na cidade do Rio de Janeiro um espaço de memória dedicado a este gênero musical nem ao Carnaval carioca”, explica Rachel Valença, consultora do projeto orçado em R $\$ 70$ milhões, a serem divididos entre o governo do estado e a Fundação Roberto Marinho. "A intenção é estabelecer no MIS um espaço de visitação e um espaço de pesquisa para especialistas, aqueles que desejam consultar livros, gravaçōes, documentos etc", conta Rachel.

Segundo ela, todo o acervo do MIS já foi examinado para determinar, nas diversas mídias, os documentos pertinentes ao tema: gravações de música em discos (78 rpm e LP), em fitas (de rolo e cassete), gravaçōes de preciosos depoimentos, documentos, fotografias, filmes. "A partir daí, iniciaram-se os estudos para a criação da museografia, ou seja, da forma como o tema será apresentado ao visitante na exposição permanente", explica a consultora. "Esses estudos ainda estão em andamento, mas é certo que se procurará fazer uso de toda a tecnologia que estimula o visitante de museu do século XXI à interatividade, sem, no entanto, ferir os valores tradicionais e sempre com a preocupação em se valorizar o passado e o modo de criação peculiar ao samba", afirma ela. O novo prédio, com projeto arrojado do arquiteto norte-americano Diller Scofidio, receberá ainda todo o acervo do atual Museu Carmen Miranda. A previsão é de que o museu seja inaugurado em 2012, podendo, assim, ser visitado pelos turistas que vêm para o Rio assistir a Copa do Mundo de 2014.

A VOZ DO MORRO, SIM SENHOR! "O RiO de Janeiro tem um potencial para se firmar como uma cultura diferenciada porque o samba que se faz aqui é único, não é igual ao de lugar nenhum", defende Kamel. "Todos esses investimentos devem fortalecer os elos históricos desse gênero musical e potencializar o samba produzido nas comunidades fluminenses, escolas de samba, pelos pagodeiros e sambistas dos botequins, criando oportunidades e ampliando o leque de novos produtos para o público", finaliza o pesquisador. Era o que já sabia o sambista Zé Keti (1921-1999) quando escreveu na letra de $A$ voz do morro: "Eu sou o samba, sou natural aqui do Rio de Janeiro, sou eu que levo a alegria para milhôes de corações brasileiros". $\mathrm{E}$, ao que parece, essa alegria quer contagiar o resto do mundo.

Patrícia Mariuzzo

\section{HISTÓRIA}

\section{ATLAS DO COMÉRCIO TRANSATLÂNTICO DE ESCRAVOS}

No dia 4 de agosto de 1816 o navio Pastora de Lima deixou o porto do Rio de Janeiro. O destino do capitão Manoel José Dias e sua tripulação era Moçambique, na África. O motivo da viagem: comprar escravos. Em terras africanas embarcaram 404 escravos, mas chegaram ao Brasil, 290. Morreram durante a travessia do Atlântico 114 homens, mulheres e crianças. Desde a saída do Rio de Janeiro, atéo retorno do Pastora, em 16 de janeiro de 1817, na Bahia, foram 165 dias de viagem. Os dados acima se referem a uma dentre as mais de 35

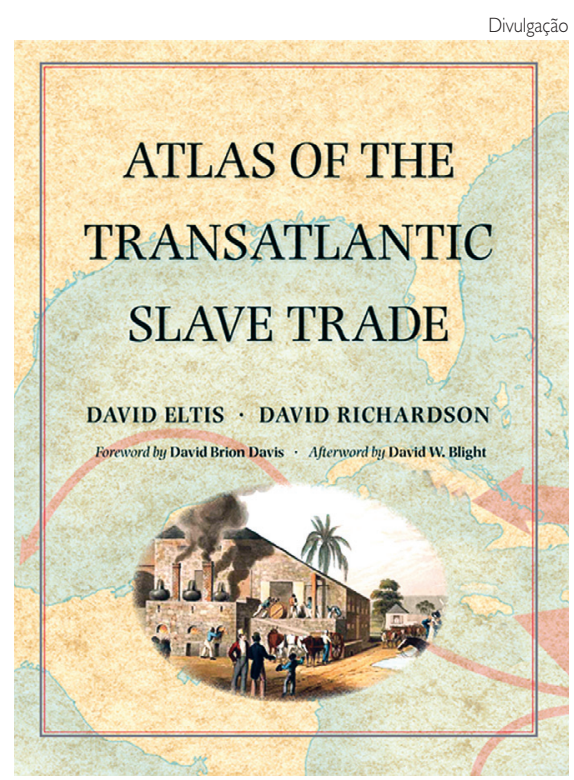

Atlas traz mapas inéditos sobre comércio de escravos na América 